\title{
Study of the means of online payment in the Portuguese population
}

\author{
Nuno Castro \\ Faculdade de Filosofia e Ciências Sociais \\ Universidade Católica Portuguesa \\ Braga, Portugal \\ nunoaac@hotmail.com \\ Henrique Santos \\ Information Systems Department \\ University of Minho \\ Guimarães, Portugal \\ hsantos@dsi.uminho.pt \\ Centro ALGORITMI \\ University of Minho \\ Guimarães, Portugal
}

\author{
Vítor J. Sá \\ Faculdade de Filosofia e Ciências Sociais \\ Universidade Católica Portuguesa \\ Braga, Portugal \\ vitor.sa@braga.ucp.pt \\ Centro ALGORITMI \\ University of Minho \\ Guimarães, Portugal \\ School of Health \\ Polytechnic of Porto \\ Porto, Portugal \\ vitorsa@ess.ipp.pt
}

\author{
Maria José Magalhães \\ Faculdade de Filosofia e Ciências Sociais \\ Universidade Católica Portuguesa \\ Braga, Portugal \\ mjmagalhaes@braga.ucp.pt \\ Department of Economics, Management, \\ Industrial Engineering and Tourism \\ University of Aveiro \\ Aveiro, Portugal \\ mjmagalhaes@ua.pt
}

\begin{abstract}
Nowadays it is possible to verify that there is a change in the way of buying, that is, the traditional means of shopping is increasingly giving way to the electronic medium and, consequently, electronic payment means.

The Internet, by making it possible to purchase and pay online, through means such as PayPal, Credit Cards, PaySafeCard, among others, has contributed to greater convenience, speed and efficiency, making the daily life of the population easier. This phenomenon gives rise to a new generation of consumers, the online consumers [1].

Therefore, the objective of this research was to understand which means of online payments are most used by consumers. As a way of responding to this objective, a quantitative methodology was used, in which an online questionnaire was created to collect data

Some results corroborate with the literature, but others contradict it, especially regarding the age range of online consumers.
\end{abstract}

Keywords- online payments; e-commerce; consumers; Internet

\section{INTRODUCTION}

E-commerce and its online payment methods have developed rapidly with the evolution of information and communication technologies, becoming topics of great importance and discussion. Nowadays, we note that more and more consumers have adhered to the e-commerce, which also has led to a greater adhesion of the companies, to expand their businesses. The Internet is considered a medium that offers several benefits for consumers, especially regarding the distance between companies and consumers [2]. To meet consumer demands, the means of payment have become simpler, faster, and safer.

The purpose of this study is to understand which online payment methods Portuguese consumers consider to be safer and which are the most used, to understand how often they buy online, and to verify if satisfaction can be related to the problems experienced by participants in buying online.

\section{LITERATURE REVIEW}

\section{A. Internet and e-Commerce}

The history of the internet involves many technological, organizational, social and political aspects. The influence of the Internet is not only present in Information and Communication Technologies, but also throughout society, as online services are increasingly used to acquire information, shop and work in community [3]. The Internet is considered one of the main means of communication worldwide, and its use and its purpose vary according to the needs of the moment of each consumer [4]. According to the National Statistics Institute, in Portugal, $64 \%$ of households have access to a computer, $58 \%$ have internet access and 10\% have placed orders through this way, according to the Survey on the Use of Information and Communication Technologies by Families [5].

It is now possible to perform numerous operations over the internet. This is considered a familiar tool for most of the world population. The emergence of the internet provided incalculable benefits to global activity. These benefits include ease of information access, entertainment, and greater proximity between people in different parts of the world. The internet thus fills few hours of everyday life in which consumers can: access their bank account, read the news, keep up-to-date on the blogs they follow, order the week's purchases and even simplify the more bureaucratic issues, such as taxes delivery. Despite the amenities and facilities offered by this medium, the internet has also become one of the most desirable targets for the malicious people, thus leading to cases of cheated consumers.

In this way, this communication medium has gained a prominent place for various organizations and companies, since it provides the infrastructure on which strategic applications are developed, namely e-commerce [6].

E-commerce arose due to the evolution of technologies on the Internet, aiming to complement the sales process and eliminate intermediary supply chain, helping in the globalization of the economy through partnerships, businesses and the reduction of geographical limits [7]. In this sense, ecommerce is understood as a combination of the traditional 
business and the automation provided by the Internet, allowing companies to exchange information, conduct business transactions, deliver and sell goods and services in an automatic way, based on a secure and innovative communication protocols, in which the potential buyers are predominantly worldwide [6].

In the same line of ideas, e-commerce can be defined through the purchase, sale and transfer of products and services that use the Internet, through a computer, a smartphone and/or a tablet, which are dependent on a secure connection [8]. E-commerce is then characterized by the commerce of products and services through the Internet, enhancing numerous advantages and disadvantages for both business and consumers. It presents as main advantages, the availability of the online store -24 hours a day, its low operating cost in relation to traditional stores, and the ease of access to new markets [9]. However, regarding the disadvantages, stands out the impossibility of touch and experiment the products, as well as the information related to payments, and the exchange/return of products [10].

In the Portuguese population it is verified that, more and more consumers are using e-commerce. A study by Marktest reveals that in the third quarter of 2013, about 4445 million citizens of mainland Portugal used e-commerce stores [28]. Those users visited 749 million pages of e-commerce sites, in an average of 169 per person, spending about six million hours on the respective webpages, which is on average an hour and 21 minutes per user [11]. Based on the above information, it is estimated that about half of the Portuguese population access e-commerce stores. This data tends to increase, since the internet is a technology present and used by a large part of the Portuguese population, either as a means of communication, as a means of research and/or as a means of acquiring products and services [11].

\section{B. Online Consumers}

Internet purchases in recent years have risen by 1.5 billion euros, to an average of 375 million euros per year. In 2015 online purchases in Portugal presented a total of around three billion euros, double the amount registered in 2010. This information was advanced by SIBS, manager of the ATM network, with Data Monitor through its study "online consumer payments analytics" and presents an analysis of the evolution of the market of electronic payments in Portugal [12]. In the process of an online purchase, when consumers identify the need to obtain a product or service, they access the internet and seek information related to that product or service. However, sometimes consumers are attracted by the information about products and services associated with the felt need to obtain it [13]. In this sense, the internet offers a wide variety of marketing information, such as links, sponsorships, product reviews, price comparison, among others. It should also be noted that the hyperlinks take the consumer directly to the pages of online stores. In this way, it can be assumed that the more consumers exploit the Internet, the more exposed they are to marketing products and information that, with the right stimulus, lead the consumer to buy on impulse [14].

In this regard, Saraiva (2012) states that consumer behaviour is related to several variables, namely: 1) gender men shop more frequently and spend more money online than women; men like shopping online more than women, since women are more sceptical of online commerce; 2) age - in relation to age and frequency of buying online the results found are mixed; 3) Frequency of Internet use - the results are mixed for the effects of the use of the internet on the intention of online shopping, in turn the use of the internet is negatively related to the perceived risk of the product; 4) ease of use - the use has a positive relation with the tendency to buy online; 5) online experience- positive online experiences have a positive influence on the intention to buy online; and, 6) satisfaction with past online purchases - satisfaction with past purchases has a positive relationship with the intention to re-buy online [15].

Based on the above data, it is pertinent to make a bridge with that of the Portuguese population. In this sense, data from the National Institute of Statistics (2014) show that men do more online purchases than women $(16.1 \%$ and $13.5 \%$, respectively). Regarding the age, it is verified that it is the age group of the 25 to 34 years that more online purchases makes, whereas from the 45 years there is a significant reduction of this type of purchases [5]. Regarding educational qualifications, data show that consumers with higher education make more purchases online $(38.9 \%)$, while consumers with secondary education do less online shopping $(25.0 \%)$ [5]. Regarding the professional situation, it is verified that students $(21.9 \%)$ and employed persons $(20.6 \%)$ are the ones that make the most purchases online compared to nonstudents and the unemployed [5].

\section{Risks and Security in Online Shopping}

Although online shopping conquers consumers more and more, there are still consumers who consider online shopping risky. Risks can be understood in various means of purchase, such as purchases at the post office, online stores, traditional stores among others [16]. When buying a product or service, the consumer is faced with the possibility of obtaining desirable gains as well as undesirable losses, since it is not possible to predict the future, making it difficult to realize the answer of the product in question. Online commerce creates in consumer the idea that online shopping involves more risk compared to purchases made in traditional commerce, since it is not possible to physically analyse the product. In online commerce, there is no direct contact with the product, which can create distrust in the consumer. In addition to not having contact with the product, the lack of personal contact in the act of the sale transaction, can also constitute a risk to the consumer [16]. This situation can be related to the risk of satisfaction, that is, the purchase made does not provide personal satisfaction as it does not meet consumer expectations [16]. In this sense, the study carried out by Crespo, Bosque and Sánchez (2009) points to the existence of six categories of online purchase risks, namely, economic, social, temporal, psychological, performance and privacy risks. The authors show that, within these categories, the risks that represent the most concern on the part of the consumers are the risks of performance and the economic ones [17]. Along the same lines, Gonçalves-Filho (2000) points out the main risks associated with online shopping: the possibility of using a credit card number for third parties, the advance payment without guarantee of having received the product and the lack of information in general [18]. In this sense, the study by Liebermann and Stashevsky (2002) shows that for both consumers and less experienced consumers, the risk factors are stealing credit card information and exposing personal data [19]. 
The authors Macieira, Carvalho and Lima (2011), point out that consumers with higher incomes present themselves with greater risk of privacy and less financial risks [20]. In turn, Hernández, Jiménez and Martín (2010) argue that income is no longer a variable that differentiates the behaviour of the high- and low-income segments, when the consumer acquires several positive experiences consuming through the internet [21]. This situation is verified, since consumption in a positive way through the internet decreases the perception of the risks associated with this same consumption [22] [23].

The question of online shopping security is thus a factor that attracted special interest, according to Liebermann and Stashevsky (2002). Although there are technological systems for website protection, that prevent that the personal data of each person are robbed, there are still consumers who believe in the lack of security in purchases made through the internet [19]. In some cases, the lack of knowledge about existing protection systems is a reason for mistrust regarding online shopping security.

\section{Means of payment online}

In the online medium, electronic payment aims to simulate existing "real world" payment mechanisms or even create new ways of performing these transactions [24]. Online forms of payment, for some consumers, still constitute a barrier. Despite the many ways to make payment, many consumers do not know how to use them, and always want the safest way to not lose your money or your product. The notion of payment is an intrinsic part of any business transaction.

In order to better understand the means of online payment, the most reliable and used by the consumer will be approached in this study, namely: 1) Credit cards, 2) MB WAY, 3) PayPal, 4) PaySafeCard, 5) Bank transfer and 6 ) Skrill and Neteller.

Regarding 1) credit cards, this is one of the most common forms of payment used by the consumer. To make payments on the internet through the credit card we only need the number, expiration date and the security code. This form has as main advantage, practical and generalized use, since most of the consumers have credit cards. As a major disadvantage, this means of payment requires extra care with its use due to possible fraud. In this sense, the consumer must make sure of the security of the site before entering the number, expiration date and security code [3].

Regarding 2) MB WAY, it is a virtual payment card. To register this card, the consumer only needs to have a debit card associated with the bank account. Later, an ID and a secret code will be assigned. In this way, whenever the consumer wants to make a payment, he / she must access the MB WAY page and create a temporary card. In turn, this card only has a single use, that is, the consumer has to create a new card every time he wants to make a payment. This means of payment presents a high degree of security, since the consumer does not need to enter the debit card data on the internet. As a disadvantage, MB WAY, when used frequently in a site, can block access to the account as a form of security, since it can be understood by the system as a possible fraud [25].

In respect to 3) PayPal, it is a widely used payment method because it allows you to make payment through your bank account or credit card (you can use MB WAY). To join this online payment means, the consumer registers on the website and later will receive a code that will allow to carry out the purchases and to load the PayPal account. This payment system, does not need of financial charges to open the account, being this one free for the user. Another advantage is that the data is safeguarded and not revealed to the websites where the consumer makes the purchase. As a disadvantage, like MB WAY, overuse can lead to account lockout for security reasons [25].

4) PaySafeCard is an ideal online payment method for young people, since the available credit limit does not exceed 100 euros. This system is fast, convenient and does not require the consumer to provide the credit card number or any other account details. This card can be purchased at any Payshop store and Post Office stores, and in the first year no administrative fees are charged to the consumer. Exceeding this period, a monthly fee of two euros will be charged for its use. The fact that it does not exceed the limit of 100 euros is a safe way for young people, as well as preventing them from carrying a lot of money. In situations where the consumer wants to make payments of more than 100 euros, this means can no longer be used, thus limiting the value to be used in purchases [3]

Referring to 5) bank transfer, this is another of the most used ways to make payments over the internet. It is practical because you can do it through the internet, via home banking, or at the nearest ATM. However, the fact that payment before the product is required may constitute a constraint on the purchase by the consumer. In addition, this means that account data must be provided at the time of payment (Wayner, 1996, cit. in [29]).

Finally, other equally popular means of payment are: 6) Skrill and Neteller. Skrill and Neteller are both e-commerce companies enabling and facilitating online payments. These offer services to individual consumers and merchants. These companies make it possible to create an e-wallet, that is, online deposit accounts. In this way, Srill and Neteller are alternatives to payment methods such as checks and money orders, facilitating online payment processes [26].

Thus, according to a survey carried out by Cetelem (2017) to 500 respondents, the electronic payment methods most used by Portuguese consumers are PayPal with $22 \%$, and $\mathrm{MB}$ WAY with $11 \%$ [27]. About the study carried out by Marktest to 1370 people, for the SIBS company (2016), Bank Transfers $22 \%$, MB WAY $20 \%$ and PayPal $12 \%$ were the online payment methods most used by the Portuguese [28]. In the study carried out by Alves (2017), in which 279 subjects were included, it was possible to verify that subjects between the ages of 18 and 35 tend to use MB WAY and PayPal as the most frequent online payment methods [2]. Considering the totality of the sample, it is verified that 110 individuals use the credit card as a means of payment online, 103 individuals use the bank transfer method, 80 use PayPal, and only 41 individuals use MB WAY.

\section{MethodOLOGY}

\section{A. Research Question and Objectives}

This study presents as a research question "What are the online payment methods most used by Portuguese consumers?" To answer this question, the following objectives were established:

1) Understand what online payment means that Portuguese consumers consider to be safer and which are the most used; 
2) Understand how often they make purchases online;

3) Check whether satisfaction can be related to the problems experienced by the participants in buying online.

\section{B. Data collection tools and data analysis techniques}

The methodology used in the present investigation is quantitative. Based on this premise, we used a questionnaire (created for this purpose) to fill online, through the Google Drive, to collect data. This was done by sending the questionnaire by e-mail. The use of the questionnaire makes it possible to demonstrate and generalize the results obtained by the research. Thus, this questionnaire has socio-demographic questions and specific questions, divided into two parts, constituting a total of 18 questions. After the data were collected, they were analysed using the software Statistical Package for the Social Sciences (IBM ${ }^{\circledR}$ SPSS $^{\circledR}$ version 23.0).

\section{Equations}

The sample of this study consists of 100 male and female participants, aged between 18 and 45 years. The choice of this age range is related to the fact that this investigation only contemplates subjects of legal age, to avoid embarrassments when completing the questionnaires. Another aspect, which was the basis of the choice of the age range, was that users and consumers were mostly individuals until the age of $44 / 45$, namely "the use of computers and the Internet is more frequent by people up to the age of 44" and online shopping is carried out mostly by people in the 25-34 age group [5].

\section{RESULTS AND DISCUSSION}

The sample of the present study consists of 100 participants, as previously mentioned, however, and after applying the filter questions (nationality of the participants and if they make purchases online), the valid cases were analysed, thus accounting for a total of 85 valid participants.

\section{A. Sample characterization}

TABLE I. SAMPLE CHARACTERIZATION

\begin{tabular}{|l|c|c|}
\hline \multicolumn{3}{|c|}{ Gender } \\
\hline & $\mathrm{N}$ & $\%$ \\
\hline Male & 34 & 40.0 \\
\hline Female & 51 & 60.0 \\
\hline \multicolumn{2}{|c|}{ Age } \\
\hline Between 18 and 27 years & 49 & 57.6 \\
\hline Between 28 and 36 years & 18 & 21.2 \\
\hline Between 37 and 45 years & 18 & 21.2 \\
\hline \multicolumn{2}{|c|}{ Academic qualifications } \\
\hline 3rd cycle & 2 & 2.4 \\
\hline High school & 17 & 20.0 \\
\hline $\begin{array}{l}\text { University attendance / } \\
\text { bachelor's degree }\end{array}$ & 8 & 9.4 \\
\hline Graduation & 20 & 23.5 \\
\hline Master & 24 & 28.2 \\
\hline PhD & 14 & 16.5 \\
\hline \multicolumn{2}{|c|}{ Professional situation } \\
\hline Student & 21 & 24.7 \\
\hline Unemployed & 5 & 5.9 \\
\hline Student worker & 6 & 7.1 \\
\hline
\end{tabular}

\begin{tabular}{|c|c|c|}
\hline \multicolumn{3}{|c|}{ Gender } \\
\hline Fmnlnvea & 52 & 6) 4 \\
\hline \multicolumn{3}{|c|}{ Rmunas net imoume } \\
\hline Up to $€ 10,000$ & 55 & 64.7 \\
\hline$€ 10,001$ to $€ 20,000$ & 19 & 22.4 \\
\hline$€ 20,001$ to $€ 30,000$ & 8 & 9.4 \\
\hline More than $€ 40,000$ & 3 & 3.5 \\
\hline Total & 85 & 100.0 \\
\hline
\end{tabular}

The sample consisted of 34 participants $(40.0 \%)$ of the masculine gender and 51 participants $(60 \%)$ of the feminine gender, counting a total of 85 participants of both genders. It consists of 49 participants $(57.6 \%)$, aged between 27 and 27 years; by 18 participants $(21.2 \%)$ between the ages of 28 and 36 years; and 18 participants $(21.2 \%)$ aged between 37 and 45 years, corresponding to a total of 85 participants. Regarding the academic qualifications of the participants, it is possible to verify that most of the participants have higher qualifications, namely the master's degree (24 participants, $28.2 \%$ ), whereas only $2.4 \%$ of the sample ( 2 participants) have high education. Concerning the professional situation of the participants the sample shows that 53 participants $(62.4 \%)$ are employed, whereas only 5 participants $(5.9 \%)$ are unemployed. It should also be noted that 21 participants $(24.7 \%)$ still say they study. Regarding the annual net income of the participants, 55 participants $(64.7 \%)$ enjoy a net annual income of up to $€ 10,000$, while only 3 participants $(3.5 \%)$ receive a net annual income of $€ 40,000$.

\section{B. Data analysis}

\section{1) Frequency with which participants buy online}

Regarding the frequency with which the participants make online purchases (Table II), it is verified that $36.5 \%$ of the sample make online purchases every 3 months.

TABLE II. FREQUENCY WITH WHICH PARTICIPANTS BUY ONLINE

\begin{tabular}{|l|c|c|}
\hline \multicolumn{3}{|c|}{ How often shop online } \\
\hline & $\mathrm{N}$ & $\%$ \\
\hline 1 time per week & 1 & 1.2 \\
\hline 1 time per month & 10 & 11.8 \\
\hline Every month & 26 & 30.6 \\
\hline Every three months & 31 & 36.5 \\
\hline Every 6 months & 17 & 20.0 \\
\hline Total & 85 & 100.0 \\
\hline
\end{tabular}

These data agree with the literature, in which it states that more and more consumers use e-commerce to make purchases. This is for many consumers a preferential means of shopping, since online stores are available 24 hours a day and are easy to use [15] [11] [12]. Another equally interesting fact is the frequency with which the participants make purchases and the gender. In this sense, considering the answers of the participants, it is verified that men (3.65) tend to buy more in online stores than women (3.61). These data corroborate the study presented by Saraiva (2012), in which he mentions that men make more purchases in online stores than women. Also the data provided by the INE (2014), affirm that the men like more to make purchases online compared to the women.

About the frequency with which the participants make online purchases according to their age, it is observed that, on average, they are the adults between 37 and 45 years old (3.72) 
who buy online more frequently, followed by young people between 18 and 27 years old $(3,67)$. This data contrasts with the data presented in the literature, where it states that it is the age group between 25 to 34 years that most purchases online, whereas from the age of 45 there is a significant reduction of this type of purchases [5].

Trying to relate the literacy and frequency with which the participants make purchases online, it is verified in this sample that, on average, the participants with university education, specifically, graduation (3.85) and masters (3.79) that more purchases online, while those with lower literacy (3rd cycle3.50, high education-3.76) are less likely to purchase online. In this sense, it is possible to mention that these data agree with the data provided by INE (2014), which show that consumers with university education make more online purchases $(38.9 \%)$, while consumers with high education do less online shopping (25.0\%) [5].

Analysing the professional situation and the frequency with which the participants make purchases, the employed participants (3.68) make, on average, more purchases than the students (3.57) and the unemployed (3.60). These data support the data presented in the literature, in which it is reported that students $(21.9 \%)$ and employed persons $(20.6 \%)$ are more likely to buy online than non-students and the unemployed [5].

\section{2) Safer and more used forms of online payment by} participant

Regarding the payment methods most used by the participants (Table III), PayPal is the form of payment used by the majority of the participants $(28.2 \%)$, followed by Credit Cards $(27.1 \%)$ and Bank transfer $(22.4 \%)$. These data are in line with the data provided by Cetelem (2017), Marktest (2016) and Alves (2017), where Portuguese consumers (22\%) report that PayPal is the most widely used online payment method, followed by Bank transfer $(22 \%)$ and credit cards (110 participants) (respectively) [27] [28] [2].

TABLE III. ONLINE PAYMENT METHODS MOST USED BY PARTICIPANTS

\begin{tabular}{|l|c|c|}
\hline \multicolumn{3}{|c|}{ Online payment methods most used by participants } \\
\hline & $\mathrm{N}$ & $\%$ \\
\hline Credit cards & 23 & 27.1 \\
\hline MB WAY & 16 & 18.8 \\
\hline PayPal & 24 & 28.2 \\
\hline PaysafeCard & 3 & 3.5 \\
\hline Bank transfer & 19 & 22.4 \\
\hline Total & 85 & 100.0 \\
\hline
\end{tabular}

Considering the gender and the online payment methods most used by the participants, it is possible to verify that women $(29.4 \%)$ tend to prefer PayPal as an online payment method, while men $(35.3 \%)$ tend to prefer the credit cards.

Based on the relationship between age and online payment methods, PayPal is the preferred form of payment for young people between the ages of 18 and 27 (28.6\% of the sample), while credit cards are the most used form of payment for adults between the ages of 37 and 45 (61.1\% of the sample). These data agree with the previously mentioned study carried out by Alves (2017), in which it was verified that subjects between the ages of 18 and 35 tend to use PayPal as the most frequent online payment method [2].
Regarding literacy and the online payment method most used, it should be noted that participants with higher education (35\%) tend to prefer credit cards and PayPal as an online payment method. While the participants with lower literacy, tend to choose as preferred means of payment (39.4\%) online bank transfer.

Regarding the online payment methods most used and the professional situation of the respondents, credit cards are the online payment method most used by the employees (34.0\%), while bank transfer is accepted by the students as the most widely used online payment method (33.3\%). In turn, PayPal is considered the online payment method most used by the participants with the worker-student status (66.7\%).

In turn, about the most secure form of payment (Table IV), the participants $(31,8 \%)$ affirm that PayPal represents the most reliable and reliable form of payment. This result may justify the previous choice of participants, since PayPal was considered the most used payment method.

TABLE IV. ONLINE PAYMENT METHODS CONSIDERED MORE SECURE

\begin{tabular}{|l|c|c|}
\hline \multicolumn{3}{|c|}{ Online payment methods considered more secure by participants } \\
\hline & $\mathrm{N}$ & $\%$ \\
\hline Credit cards & 15 & 17.6 \\
\hline MB WAY & 17 & 20.0 \\
\hline Paypal & 27 & 31.8 \\
\hline PaysafeCard & 5 & 5.9 \\
\hline Bank transfer & 21 & 24.7 \\
\hline Total & 85 & 100.0 \\
\hline
\end{tabular}

3) Relation between satisfaction in purchase and online payment and problems experienced by the participants in buying online

Regarding the satisfaction with purchase and online payment method used by the participants (Table V), it is possible to verify that $54.0 \%$ of the sample states that they feel quite satisfied with their purchase and with the online payment medium used, whereas only $11.8 \%$ classifies as indifferent to their purchase and the means of payment used.

TABLE V. SATISFACTION WITH PURCHASE AND ONLINE PAYMENT METHOD

\begin{tabular}{|l|c|c|}
\hline \multicolumn{3}{|c|}{ Satisfaction with purchase and online payment method } \\
\hline & $\mathrm{N}$ & $\%$ \\
\hline Not satisfied & 1 & 1.2 \\
\hline Indifferent & 10 & 11.8 \\
\hline Fairly Satisfied & 46 & 54.0 \\
\hline Totally Satisfied & 28 & 32.9 \\
\hline Total & 85 & 100.0 \\
\hline
\end{tabular}

Regarding the problems experienced by participants in online shopping (Table VI), it is verified that a great majority, $78.8 \%$ of the sample, never had problems in making purchases in online stores.

TABLE VI. PROBLEMS EXPERIENCED BY PARTICIPANTS IN BUYING ONLINE

\begin{tabular}{|l|c|c|}
\hline \multicolumn{3}{|c|}{ Problems experienced by participants in buying online } \\
\hline & $\mathrm{N}$ & $\%$ \\
\hline Yes & 18 & 21.2 \\
\hline No & 67 & 78.8 \\
\hline
\end{tabular}




\begin{tabular}{|c|c|c|}
\hline \multicolumn{3}{|c|}{ Problems experienced by participants in buying online } \\
\hline Total & 85 & 100.0 \\
\hline
\end{tabular}

Relating satisfaction with purchases and online payments and the problems experienced by participants in online shopping, it was possible to verify, through Spearman's correlation coefficient, that there is a statistically significant negative correlation between these two variables $(\mathrm{Rs}=-0.330$, $\mathrm{p}=0.002$ ). In this sense, participants' satisfaction with purchases and online means of payment increases when there are no problems associated with online shopping. Thus, the absence of problems translates into greater satisfaction with online purchases and payments. These data are in line with the data presented in the literature, specifically in the study by Saraiva (2012), which states that positive online experiences have a positive influence on the intention to buy online, as well as satisfaction with past purchases has a positive relationship with the intention of buying back online [15]. The ease of use of online payment means also shows a positive relationship with the buying trend.

\section{CONCLUSION}

E-commerce and online payment methods are increasingly being used by Portuguese consumers. In 2015, online purchases in Portugal totalled around 3 billion euros, double the value registered in 2010. Therefore, the use of online payment means also increased and was specified, to give response to consumers. In the same line of ideas, it was possible through the present study to verify that some results agree with the data presented in the literature, while others do not.

As results that corroborate the literature, stands out the frequency with which consumers make online purchases. Both in the literature and in the results of the sample, the participants tend to buy more and more through online stores. In terms of online payment means, the results obtained are also in line with the data pointed out in the literature, which states that PayPal is the most widely used online payment method for consumers, followed by credit cards and of bank transfers.

Regarding the satisfaction with the purchase and the means of payment used in relation to problems experienced by the participants in buying online, it is verified that there is a statistically significative negative correlation. In this sense, the absence of problems translates into greater satisfaction with online purchases and payments.

As results that contradict the literature, the frequency with which the participants make online purchases according to the age stands out. In the present study, adults between 37 and 45 years of age purchase online more frequently, and not young people, as suggested by the literature.

The present research has as main limitation the number of participants. Because it contains a small data sample $(n=85)$, it may have led to the loss of relevant information.

\section{ACKNOWLEDGMENT}

This work has been supported by COMPETE: POCI-010145-FEDER-007043 and FCT - Fundação para a Ciência e Tecnologia within the Project Scope: UID/CEC/00319/2013.

\section{REFERENCES}

[1] Albertin, A. L., \& De Moura, R. M. (1998). Comércio eletrónico: Seus aspetos de segurança e privacidade. Revista de Administração de Empresas, 38(2), 49-61.

[2] Alves, D. R. (2017). E-commerce: um novo caminho para o método de pagamento. Dissertação de Mestrado, Instituto Superior de Economia e Gestão. Lisboa: Universidade de Lisboa.

[3] Lacão, S. F. D. S. (2016). O que leva os consumidores portugueses a fazerem compras online em sites de roupa e não em lojas físicas. Dissertação de Mestrado. Lisboa: Universidade Lusófona de Humanidades e Tecnologias.

[4] Esteves, Andreia Filipa Pinto (2014). "Usuabilidade em websites : o caso da Ticketline". Dissertação de Mestrado, Universidade de Lisboa. Instituto Superior de Economia e Gestão.

[5] INE (2014) Sociedade da Informação e do Conhecimento - Inquérito à Utilização de Tecnologias da Informação e da Comunicação nas Famílias. Instituto Nacional de Estatística, Portugal.

[6] Fernandes, E. M. (2011). E-commerce e a internacionalização empresarial: o caso prático da Salsa. Dissertação, Universidade do Minho, Escola de Economia e Gestão. Braga: Universidade do Minho.

[7] Nascimento, N. P. F. (2015). Estudo sobre as empresas integradoras de pagamentos online: as vantagens e os riscos para o comércio eletrônico. REFAS: Revista FATEC Zona Sul, 1(2), 4.

[8] Kuhler, J. (2013). "Computer Engineering." Salem Press Encyclopedia Of Science: Research Starters.

[9] Diniz, L.L., Souza, L.G., Conceição, L.R., \& Faustini, M. R. (2011). III Encontro Cientifico e Simpósio de Educação Unisalesiano. O Comercio eletrónico como ferramenta estratégica de vendas para empresas.

[10] Conceição, V. O. (2006). Comércio Eletrónico. Brasília.

[11] ACEPI (2013). 4,4 Milhões de portugueses em sites de e-Commerce entre julho e setembro. Portugal. Obtido em 27 de janeiro de 2018, de $\mathrm{http} / / /$ www.acepi.pt/artigoDetalhe.

[12] SIBS (2015). Online consumer payments analytics. Report, SIBS, Portugal.

[13] Malik, G., \& Guptha, A. (2013). An empirical study on behavioral intent of consumers in online shopping. Business Perspectives and Research, 13-28.

[14] Moe, W. (2003). Buying, searching, or browsing: differentiating between online shoppers using in-store navigational clickstream. Journal of Consumer Psychology, 13(1,2), 29-39.

[15] Saraiva, C. M. (2012). Determinantes do comportamento de compra online. Dissertação, Instituto Politécnico de Lisboa. Escola Superior de Comunicação Social, Lisboa.

[16] Sousa, A.G., Mattosinho, C. M., Costa, M. F. (2009). Risco percebido em compra pela internet: Um estudo do comportamento do consumidor na compra de automóveis.

[17] Crespo, A. H., Bosque, I. R., \& Sánchez, M. M. (2009). The influence of perceived risk on Internet shopping behaviour: a multidimensional perpective. Journal of Risk Research, 12 (2), 259-277.

[18] Gonçalves-Filho, C. (2000). Comércio eletrônico na Internet: uma pesquisa exploratória no mercado consumidor. Revista de Administração FACES Journal, 1(1), 81-94.

[19] Liebermann, Y., \& Stashevsky, S. (2002). Perceived risks as barriers to Internet an e-commerce usage. Qualitative Market Research , 4(5), 291-300.

[20] Macieira, M., Carvalho, F., \& Lima, V. (2011). Fatores demográficos na percepção do risco de compra pela Internet: o caso de um site brasileiro de venda de ingressos. Revista portuguesa e Brasileira de Gestão, 10(1-2), 92-101.

[21] Hernández, B., Jiménez, J., \& Martín, M. J. (2010). Age, gender and income: do they really moderate online shopping behaviour? Online Information Review, 35(1), 113-133.

[22] Hernández, J. M. (2004). Porque algumas pessoas compram mais que outras pela Internet: o papel do conhecimento e do risco percebido. Gestão.Org, 2(2), 98-111.

[23] Kotler, P., \& Keller, K. L. (2006). Administração de Marketing: A Bíblia do Marketing (12 ed.). São Paulo: Pearson Prentice Hall.

[24] Ureche, O. and Plamondon, R. (2000). Digital Payment Systems for Internet Commerce of the art. École Polytechnique de Montréal. Canada.

[25] Aigbe, P., \& Akpojaro, J. (2014). Analysis of Security Issues in Electronic Payment Systems. 
[26] Casino City (2004). Online Casino City. Acedido 06 novembro, 2017 em http://online:casinocity.com/

[27] Cetelem (2017). Literacia Financeira em Portugal, 2017. Portugal: Observador. Disponível em: https://www.cetelem.pt/oobservador
[28] Marktest (2016). Smartphone continua a crescer em Portugal. Disponível em: https://www.marktest.com

[29] Diniz, E. H. (1999). Comércio eletrónico: Fazendo negócios por meio de Internet. RAC, (1), 1-16. 